\title{
Game-theoretic analysis of supply chain coordination under advertising and price dependent demand
}

\author{
Mona Taheri", Seyyede Rozita Ebrahimi and Farid Khoshalhan
}

Department of Industrial Engineering, K.N.Toosi University of Technology, Tehran, Iran

CHRON I C L E ABSTRACT

\begin{tabular}{l} 
Article history: \\
Received September 202013 \\
Received in Revised Format \\
April 22014 \\
Accepted April 52014 \\
Available online \\
April 92014 \\
\hline Keywords: \\
Decentralized supply chain \\
Supply chain coordination \\
Revenue sharing contract \\
Game theory
\end{tabular}

\begin{abstract}
Supply chain members cannot act independently and they need to act as a part of a unified system and coordinated with other members. Therefore, a coordination mechanism may be necessary to motivate members to achieve coordination. In this paper, the coordination problem is studied in a two-level supply chain consisting of a supplier and a retailer where demand is a function of price and advertising expenditures in two scenarios. The first scenario is "No coordination", and the other scenario is "coordination with Revenue sharing contract". The models are solved using game theory, Cooperative and Nash equilibrium. Finally, numerical examples are presented indicating that the average expected profit in the second scenario, coordination with revenue sharing, is higher than the first scenario. In addition numerical examples indicate that as price and advertising elasticity to demand increase, profitability of supply chain decreases.
\end{abstract}

\section{Introduction}

The intensive competition in today's global market, the availability of various products with short life cycles and increasing customers' expectations have forced many businesses to invest more and to pay more attention to their supply chains. Meanwhile, the recent advances on communication technology and transportation have created incentives for sustainable development and supply chain management practices (Simchi-Levi, 2009). However, since various parts of the supply chains are constantly looking for profit maximization, they pay less attention on the entire supply chain's profitability. Centralized system is more secure for supply chain coordination, but may not be always true. On the other hand, in a decentralized system, supply chain members make decision regardless of their decision's effect on the performance of the other members and the entire supply chain. This is the key issue in supply chain management to develop an appropriate mechanism such that various objectives are aligned, and integrate their activities to optimize the entire system. In recent years, the issue of setting some contracts for supply chain coordination has attracted much attention among researchers. Supply chain contracts are useful tools for communication and coordination among supply chain members in a decentralized system. The contract can be defined as an agreement between the two sectors. The

* Corresponding author.

E-mail: trmona68@yahoo.com (M. Taheri)

(C) 2014 Growing Science Ltd. All rights reserved.

doi: $10.5267 /$ j.ijiec.2014.4.003 
contracts imply conditions that offer appropriate information and incentive mechanisms, and ensure all parts of supply chain to achieve coordination and optimal performance of supply chain.

There are literally various types of contracts used in the literature to coordinate the supply chain such as quantity discount contract (Weng, 1995), revenue sharing contract (Cachon, 2003), quantity flexibility contract (Tsay, 1999), and buy back contract (Pasternack, 2008). According to Lovejoy (1999), quantity flexibility contracts have been used by Toyota and by Nippon Otis as a manufacturer of elevator equipment. Connors et al. (1995) mentioned that quantity flexibility contracts could improve sales' figures. Chopra and Meindl (2004) mentioned that quantity flexibility contracts are common for components in the electronic and computer industry. According to Chopra and Meindl (2004), Benetton as a fashion clothing manufacturer used these contracts with its retailers to increase supply chain profits. If buyback contracts, revenue sharing contracts and quantity flexibility contracts are properly implemented, they will increase profit of both parties resulting in a win-win situation (Cachon, 2003; Chopra \& Meindl, 2004). However, will these benefits carry over if demand is price dependent? Cachon and Lariviere (2005) studied a vendor managed inventory contract with revenue sharing and demonstrated that the decentralized system could provide less capacity than the integrated system. Hua and $\mathrm{Li}$ (2008) proposed a cooperative game model to describe the payment bargaining process between the manufacturer and the retailer, and determined a new consignment contract with revenue sharing.

Pasternack (2008), Kandel (1996) and Emmons and Gilbert (1998) are among some pironners who performed comprehensive studies on the buyback contract. Yao et al. (2008) presented a price dependent demand model, with buyback contract. Leng and Parlar (2010) studied a model for coordinating decentralized supply chain, evaluated buy back contract, lost sales contract and cost sharing contract, and used game theory to solve the model. Emmons and Gilbert (1998) studied a model of price dependent demand where buyback policies would benefit both the retailer and the manufacturer. The authors showed that while the wholesale price is in a certain range, the manufacturer chooses a positive buyback price over not offering a buyback price. Mahajan (2008) used the same price dependent demand model originally developed by Emmons and Gilbert (1998) and considered a revenue sharing contract. They reported an existence of a positive revenue sharing ratio that the manufacturer would prefer. He also used the same model of price dependent demand as Emmons and Gilbert (1998) and considered the quantity flexibility contract. Finally, Wang and $\mathrm{Hu}$ (2010) considered a model with effort dependent demand with buy back contract, revenue sharing contract and quantity flexibility contract.

Literature review indicates that in supply chain coordination with price and advertising dependent demand, revenue sharing contract and quantity flexibility contract were rarely considered using game theory approach. In this paper, two scenarios of "without coordination" and "coordination revenue sharing contract" are considered. For each scenario, a model with price and advertising dependent demand is presented for a two-level supply chain consisting of a client and supplier. The models are solved in two solutions using game theory including Cooperative and Nash equilibrium. Numerical results are presented for two cases, to clearly show the effect of coordination on supply chain performance. Numerical results indicate that the contracts can increase profit of supply chain.

This paper is organized as following; in section 2 the model is formulated, in section 3 the solution for the model is presented, in section 4 numerical samples are solved, and finally conclusions are presented in section 5 .

\section{Research methodology}

Consider a two-stage supply chain with a supplier and a retailer. The retailer is a newsvendor who faces an uncertain customer demand $D$, which depends on price and advertising. The methodology used in this study is described in Fig. 1. 


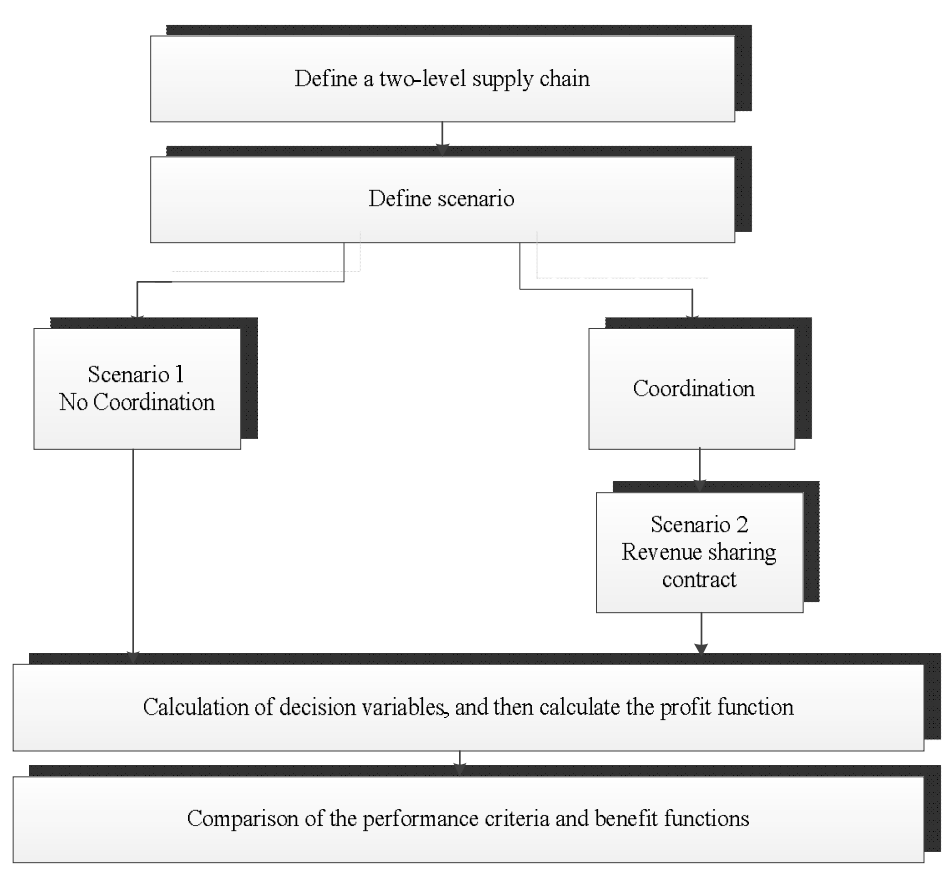

Fig. 1. Procedure for comparison

\subsection{Assumptions}

- A two-level supply chain consists of a retailer and a supplier.

- The model is in a form of a single period model.

- There is only one single product.

- The demand is stochastic and depends on price and advertising and it is considered the same for comparing all contracts as follows,

$D(p, E)=\alpha p^{-\beta} E^{\delta}+\varepsilon$,

where $\alpha$ is the initial demand, $\beta$ and $\delta$ are price and marketing elasticity to demand, respectively and finally $\varepsilon$ represents residuals, which has a uniform distribution on the interval $[a, b]$.

\subsection{Notation}

$c$ : Production cost

$D(p, E)$ : Annual demand (depend upon price and advertising)

$E\left(\pi_{s}\right)$ : expected profit of supplier

$E\left(\pi_{r}\right)$ : expected profit of retailer

$E\left(\pi_{s c}\right)$ : expected profit of whole supply chain $\left(E\left(\pi_{r}\right)+E\left(\pi_{s}\right)\right)$

$q$ : optimal order quantity

$w$ : wholesale price charged by supplier per unit

$p$ : selling price per unit

$E$ : advertising cost

Decision variables for Revenue sharing contract: 


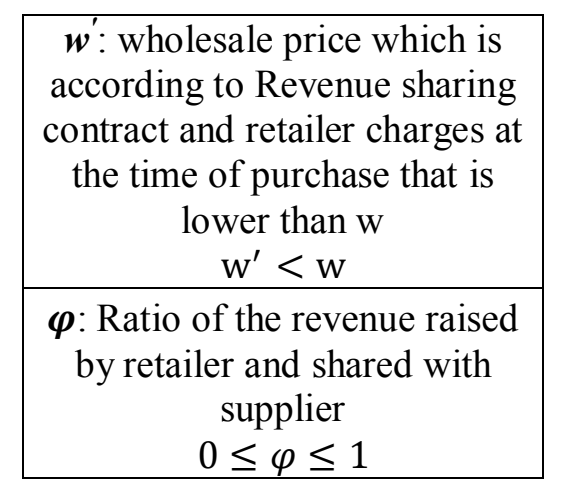

The unit cost and unit price should follow the following constraints because of the value addition at different stages of S.C:

$$
c(\text { production cost }) \leq w(\text { wholesale price })<p \text { (price of product })
$$

\section{Mathematical Modeling}

The contracts help the supply chain members achieve coordination, which would lead to improved supply chain performance. To realize the importance of coordination by contracts, two scenarios have been explored. The first scenario is "No coordination" in which the S.C. members act independently, and the second scenario is "coordination with Revenue sharing contract". The various performance measures of the first scenario are compared with the case of coordination.

\subsection{Scenario 1: No coordination}

In this case, there is no coordination between the retailer and supplier. The retailer determines his/her optimal order quantity and the supplier provides the order, and does not do any effort to encourage the retailer make any more orders.

\subsubsection{Profit function of retailer}

In this case, the retailer's revenue is derived from selling the product to customers, and his/her costs are expenses of advertising and expenses of buying the product.

$\pi_{r}= \begin{cases}p D-w q-E & a \leq D<q \\ p q-w q-E & q \leq D \leq b\end{cases}$

As mentioned in the assumptions, the demand function is considered as a function of price and advertising, so Eq. (1) is replaced with $D$ in the retailer's expected profit function.

$E\left(\pi_{r}\right)=\int_{a}^{q} p\left(\alpha p^{-\beta} E^{\delta}+x\right) f(x) d(x)+\int_{q}^{b} p q f(x) d(x)-w q-E$

In this problem, $x$ has uniform distribution in the interval $[a, b]$. Thus, in Eq. (3), $f(x)$ equals to $\frac{1}{b-a}$. If integration in Eq. (3) is performed, the retailer's expected profit function will be obtained as following.

$E\left(\pi_{r}\right)=\frac{1}{b-a}\left[p q(b-q)+p\left[\left(\alpha p^{-\beta} E^{\delta}\right)(q-a)+\frac{(q-a)^{2}}{2}\right]\right]-w q-E$ 


\subsubsection{Profit function of supplier}

The supplier provides the retailer's order, so his/her revenue is earned from selling the product to the retailer. The equation is formulated as following:

$E\left(\pi_{s}\right)=q(w-c)$

\subsection{Scenario 2: coordination with Revenue sharing contract}

Based on the revenue sharing contract, the supplier reduces the wholesale price from $w$ to $w^{\prime}$ and the retailer shares the ratio $(\varphi)$ of the revenues earned with supplier. Retailer and supplier profit function for this scenario is formulated in Eq. (8) and Eq. (11).

\subsubsection{Profit function of retailer}

In this case, retailer's revenue is earned from selling product to the client who shares the ratio with supplier, according to the contract. In contrast, the retailer pays less to buy products from supplier.

$\pi_{r}= \begin{cases}\varphi p D-w^{\prime} q-E & a \leq D<q \\ \varphi p q-w^{\prime} q-E & q \leq D \leq b\end{cases}$

$E\left(\pi_{r}\right)=\int_{a}^{q} \varphi p\left(\alpha p^{-\beta} E^{\delta}+x\right) f(x) d(x)+\int_{q}^{b} \varphi p q f(x) d(x)-w^{\prime} q-E$

Similar to the previous scenario, Eq. (1) is replaced with $D$ and $f(x)$ equals to $\frac{1}{b-a}$. So the retailer's expected profit function is obtained as Eq. (8) derived from Eq. (4).

$E\left(\pi_{r}\right)=\frac{\varphi}{b-a}\left[p q(b-q)+p\left[\left(\alpha p^{-\beta} E^{\delta}\right)(q-a)+\frac{(q-a)^{2}}{2}\right]\right]-w^{\prime} q-E$

\subsubsection{Profit function of supplier}

For the revenue sharing contract, the profit function of supplier is:

$$
\begin{aligned}
& \pi_{s}= \begin{cases}(1-\varphi) p D+w^{\prime} q-c q & a \leq D<q \\
(1-\varphi) p q+w^{\prime} q-c q & q \leq D \leq b\end{cases} \\
& E\left(\pi_{s}\right)=w^{\prime} q-c q+\int_{a}^{q}(1-\varphi) p\left(\alpha p^{-\beta} E^{\delta}+x\right) f(x) d(x)+\int_{q}^{b}(1-\varphi) p q f(x) d(x)
\end{aligned}
$$

Eq. (1) is replaced with $D$ and $f(x)$ equals to $\frac{1}{b-a}$, and the supplier's expected profit function will change as per Eq. (11) 
$E\left(\pi_{s}\right)=\frac{(1-\varphi)}{b-a}\left[p q(b-q)+p\left[\left(\alpha p^{-\beta} E^{\delta}\right)(q-a)+\frac{(q-a)^{2}}{2}\right]\right]+w^{\prime} q-c q$

\section{Solution}

In this section, two game-theoretic models based on a non-cooperative games including Nash and a cooperative are discussed. Solution methodology is described in Fig. 1.

\subsection{Nash game}

When the manufacturer and the retailer have the same decision power, they determine their strategies, independently and simultaneously. This situation is called as a Nash game and the solution to this structure is the Nash equilibrium. The results of solving the model for two scenarios are as follows.

\subsubsection{Scenario1: No coordination}

As illustrated in Fig. 1, the amount of $q$ based on $p$ and $E$ is obtained by take the derivative of the retailer's expected profit function.

By replacing $q$ in the expected profit function of retailer, we can obtain the values of $p$ and $E$ :

$$
\begin{aligned}
& J(\beta-\delta)-\ln \left(\frac{\alpha\left(1-\beta-e^{J}(1-2 \beta)\right)}{b\left(e^{J}-1+w\right)}\right)-\delta \ln \left(\frac{\delta b\left(w+e^{J}-1\right)\left(w(1-\beta)+\beta e^{J}\right)}{\left(1-\beta-e^{J}(1-2 \beta)\right)^{2}}\right)=0 \\
& p^{*}=e^{J} \\
& E^{*}=\frac{\delta b p^{*}\left(w+p^{*}-1\right)\left(w(1-\beta)+\beta p^{*}\right)}{\left(1-\beta-p^{*}(1-2 \beta)\right)^{2}} \\
& q^{*}=\frac{b\left(w+\beta p^{*}-\beta w\right)}{1-\beta-p^{*}+2 \beta p^{*}}
\end{aligned}
$$

\subsubsection{Scenario 2: coordination with Revenue sharing contract}

In this section, we present the decision variables of retailer for the scenario that retailer and supplier agree to cooperate with Revenue sharing contract. These values are obtained according to the methodology which is shown in Fig. 2 and it is quite similar to previous scenario.

$$
\begin{aligned}
& H(\beta-\delta)-\ln \left(\frac{\varphi \alpha\left(1-\beta-e^{H}(1-2 \beta)\right)}{b\left(\varphi\left(e^{H}-1\right)+w^{\prime}\right)}\right)-\delta \ln \left(\frac{\delta b\left(w^{\prime}+\varphi\left(e^{H}-1\right)\right)\left(w^{\prime}(1-\beta)+\beta \varphi e^{H}\right)}{\varphi\left(1-\beta-e^{H}(1-2 \beta)\right)^{2}}\right)=0 \\
& p^{*}=e^{H} \\
& q^{*}=\frac{b\left(w^{\prime}+\beta \varphi p^{*}-\beta w^{\prime}\right)}{\varphi\left(1-\beta-p^{*}+2 \beta p^{*}\right)}
\end{aligned}
$$


$E^{*}=\frac{\delta b p^{*}\left(w^{\prime}+\varphi\left(p^{*}-1\right)\right)\left(w^{\prime}(1-\beta)+\beta \varphi p^{*}\right)}{\varphi\left(1-\beta-p^{*}(1-2 \beta)\right)^{2}}$

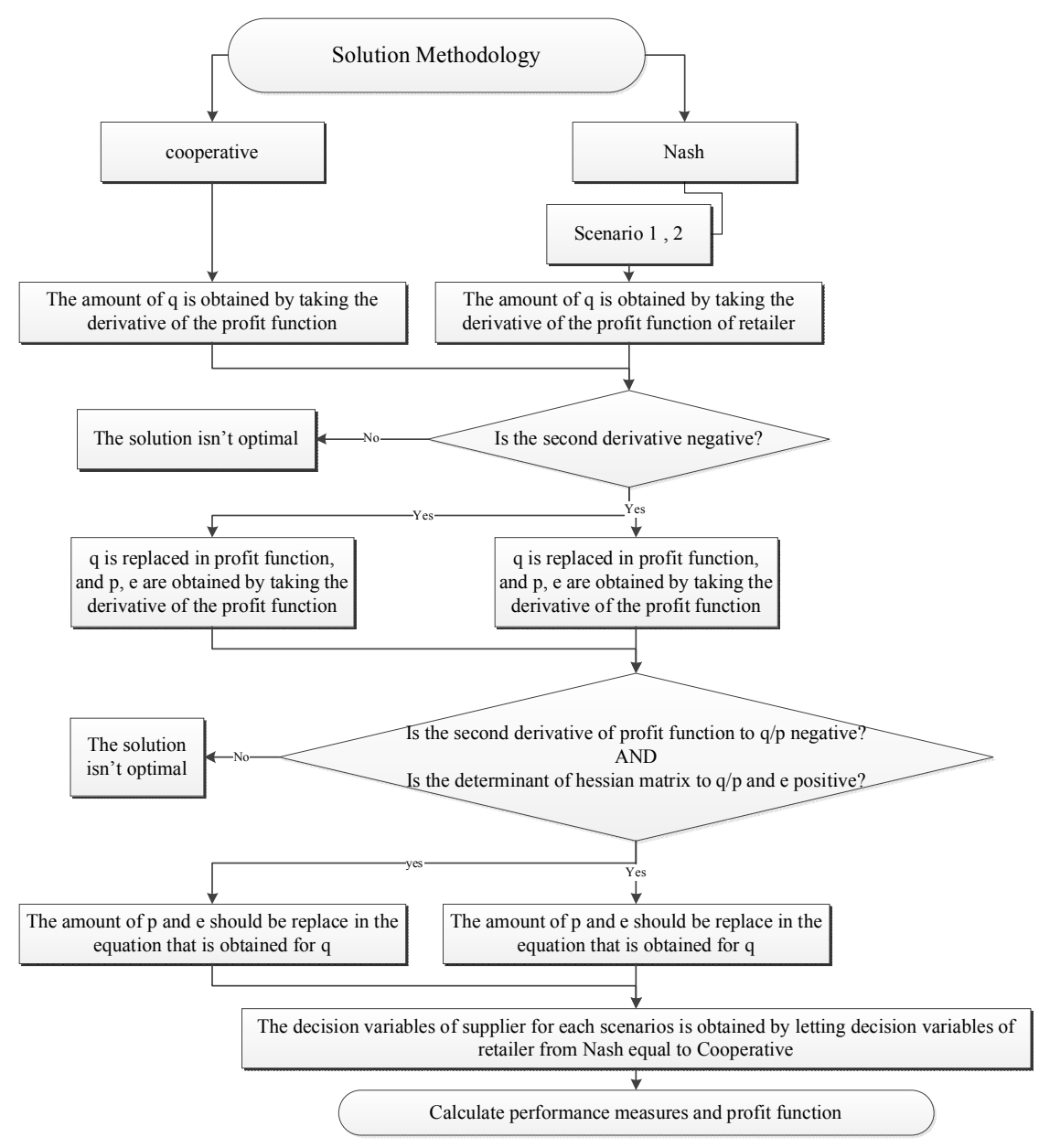

Fig. 2. Solution Methodology

\subsection{Cooperative game}

In previous subsection, a non-cooperative game was discussed. Now we model the supplier-retailer relationship as a cooperative game in which both channel members agree to cooperate and maximize the profit of the whole system. The cooperation expected profit function is the same as Eq. (20)

$\pi_{s c}=q(w-c)-w q-e+\frac{1}{b-a}\left[p q(b-q)+p\left[\left(\alpha p^{-\beta} E^{\delta}\right)(q-a)+\frac{(q-a)^{2}}{2}\right]\right]$

$k(\beta-\delta)-\ln \left(\frac{\alpha\left(1-\beta-e^{k}(1-2 \beta)\right)}{b\left(e^{k}-1+c\right)}\right)-\delta \ln \left(\frac{\delta b\left(c+e^{k}-1\right)\left(c(1-\beta)+\beta e^{k}\right)}{\left(1-\beta-e^{k}(1-2 \beta)\right)^{2}}\right)=0$

$p^{*}=e^{k}$

$q^{*}=\frac{b\left(c+\beta p^{*}-\beta c\right)}{1-\beta-p^{*}+2 \beta p^{*}}$ 
$E^{*}=\frac{\delta b p^{*}\left(c+p^{*}-1\right)\left(c(1-\beta)+\beta p^{*}\right)}{\left(1-\beta-p^{*}(1-2 \beta)\right)^{2}}$

Proof for the optimality of the obtained solution is presented in the Appendix.

As we know, when the condition of a decentralized supply chain is closer to integration channel, it means supply chain members act more coordinated. Therefore, in this paper, we suppose the retailer's decision variables coincide with the decision variables of integrated channel. As mentioned in Fig. 2, the supplier's decision variables for the second scenario is obtained by letting the retailer's decision variables from Nash game equal to cooperative game as following:

$w^{\prime}=\frac{\varphi\left(\beta e^{k}-\beta c+2 c \beta e^{H}-\beta e^{H}+c-c e^{H}\right)}{1-\beta-e^{k}(1-2 \beta)}$

\section{Numerical Example and Numerical analysis}

First, we describe the experimental parameters used in the numerical analysis for the model. Then we analyze these results and get better view over the contract properties for industrial practice. Table 1 shows the improvements provided by contract in a supply chain performance.

Table 1

Optimal solutions of scenario 1 and Scenario 2

\begin{tabular}{|c|c|c|c|c|c|c|c|c|c|c|c|c|c|c|}
\hline \multirow[b]{2}{*}{$\beta$} & \multirow[b]{2}{*}{$\delta$} & \multicolumn{7}{|c|}{$\begin{array}{c}\text { Scenario } 1 \\
\text { (No coordination) }\end{array}$} & \multicolumn{6}{|c|}{$\begin{array}{c}\text { Scenario } 2 \\
\text { (Coordination with Revenue sharing) }\end{array}$} \\
\hline & & $\mathrm{p}^{*}$ & $\mathrm{q}^{*}$ & $\mathrm{E}^{*}$ & $\mathrm{E}\left(\pi_{\mathrm{r}}\right)$ & $\mathrm{E}\left(\pi_{\mathrm{s}}\right)$ & $\mathrm{E}\left(\pi_{\mathrm{sc}}\right)$ & $\mathrm{w}^{\prime *}$ & p* & $\mathrm{q}^{*}$ & $\mathrm{E}^{*}$ & $\mathrm{E}\left(\pi_{\mathrm{r}}\right)$ & $\mathrm{E}\left(\pi_{\mathrm{s}}\right)$ & $\mathrm{E}\left(\pi_{\mathrm{sc}}\right)$ \\
\hline \multirow{3}{*}{5} & 10 & 9.025013 & 48.07 & 563.23 & 16312 & 48.07 & 16358 & 0.8443 & 7.389 & 52.357 & 368.632 & 62146.4 & 15757.3 & 77903.7 \\
\hline & 20 & 7.893187 & 46.94 & 982.95 & 8261.8 & 46.94 & 8308.7 & 0.8447 & 6.554 & 51.915 & 654.389 & 35581.05 & 9061.763 & 44642.813 \\
\hline & 30 & 6.903303 & 45.62 & 1284.4 & 2159.2 & 45.62 & 2207.3 & 0.8452 & 5.812 & 51.408 & 871.174 & 11729.18 & 3027.353 & 14756.533 \\
\hline \multirow{3}{*}{15} & 10 & 6.03756 & 38.84 & 102.44 & 2087.4 & 38.84 & 2121.8 & 0.8501 & 5.155 & 46.089 & 73.1946 & 7503.634 & 1921.667 & 9425.301 \\
\hline & 20 & 5.28039 & 36.8 & 175.45 & 1116.9 & 36.8 & 1153.7 & 0.8509 & 4.572 & 45.274 & 129.468 & 4465.791 & 1151.696 & 5617.487 \\
\hline & 30 & 4.618177 & 34.41 & 223.36 & 291.54 & 34.41 & 330.38 & 0.8518 & 4.055 & 44.326 & 171.556 & 1658.316 & 435.7668 & 2094.0828 \\
\hline \multirow{3}{*}{25} & 10 & 4.039012 & 30.46 & 35.648 & 404.53 & 30.46 & 427.48 & 0.8537 & 3.597 & 42.24 & 29.25 & 1885.526 & 491.026 & 2376.552 \\
\hline & 20 & 3.532479 & 27.04 & 58.073 & 255.47 & 27.04 & 282.51 & 0.855 & 3.19 & 40.889 & 51.4002 & 1194.815 & 314.3642 & 1509.1792 \\
\hline & 30 & 3.089471 & 22.95 & 68.292 & 68.003 & 22.95 & 98.464 & 0.8565 & 2.829 & 39.288 & 67.4838 & 519.8481 & 140.1115 & 659.9596 \\
\hline \multirow{3}{*}{35} & 10 & 2.702021 & 17.43 & 11.438 & 22.4111 & 17.43 & 30.685 & 0.8587 & 2.509 & 36.891 & 13.7459 & 502.8722 & 135.7754 & 638.6476 \\
\hline & 20 & 2.363161 & 11.4 & 14.039 & 19.286 & 11.4 & 26.4052 & 0.8609 & 2.226 & 34.548 & 23.6822 & 363.9086 & 99.52701 & 463.43561 \\
\hline & 30 & 2.066797 & 3.994 & 6.9928 & 7.9258 & 3.994 & 25.356 & 0.8635 & 1.974 & 31.689 & 30.1613 & 199.8395 & 56.10347 & 255.94297 \\
\hline
\end{tabular}

As indicated in the table, the improvements for both of the supplier and retailer can be considerable. For example, when $\beta$ is 15 and $\delta$ is 10 , for the case of "No coordination", the whole supply chain profit is 2121.8 and for the other scenario it is 9425.301 . So obviously, the expected profit of the whole supply chain increases when contracts are used. The experimental parameters used are as following. First, consider the parameters of $\alpha$ (the primary demand) and $\beta$ (consumer's price-sensitivity). In the literature, Yao (2008) considered three states for $\alpha$ and $\beta$ :

$\alpha=20, \beta=0.01,0.1,1.5,2 \quad \alpha=200, \beta=5,15,25,35,45 \quad \alpha=2000, \beta=1,10,100,200$

He proved that in case of $\frac{\alpha}{\beta}<15$, the results are difficult to interpret and if 200 units is added up to the upper bound of $\frac{\alpha}{\beta}$, it will lead to very high retail price and very small order quantity. In this article we select the results calculated by letting $\alpha=200$ and $\beta=5,15,25,35$ to analyze the performance of the different scenarios. The consumer's price-sensitivity $(\delta)$ is considered to be $10,20,30$. In addition, we let the production cost as $c=1 \$ /$ unit, the wholesale price as $w=2 \$ /$ unit and the decision variable as 
$\varepsilon \sim U[0,100]$. For scenario 2 we assume $\varphi=0.8$. The results used to conduct our analysis, have been tabulated in Table 1 implying the scenariol and scenario 2.

Let's observe contracts behavior by comparing results. The supplier's profit and retailer's profit in the scenario that contract is considered, is generally larger than the corresponding profit in the case of "No coordination". This means both the retailer and the manufacturer have earned more profit than what they would earn in a "No coordination" case. For each of two scenarios, by increasing of $\beta$, retailer's expected profit $\left(\pi_{r}\right)$ decreases, on the other hand, by increasing of $\delta$, both $\pi_{s}$ and $\pi_{r}$ decrease, this means if the customer's sensitivity to advertising increases, retailer and supplier will achieve lower profit. Also by increasing $\beta$, supplier's profit for the scenario 2 decreases.
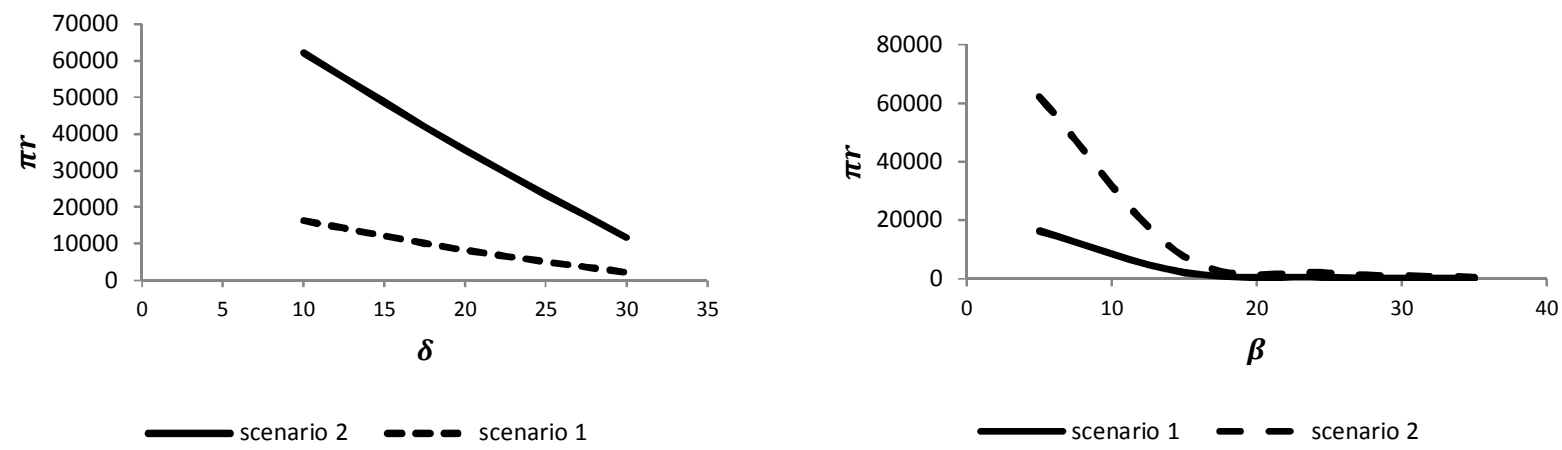

Fig 3. The retailer's expected profit function in terms of " $\beta$ " and " $\delta "$
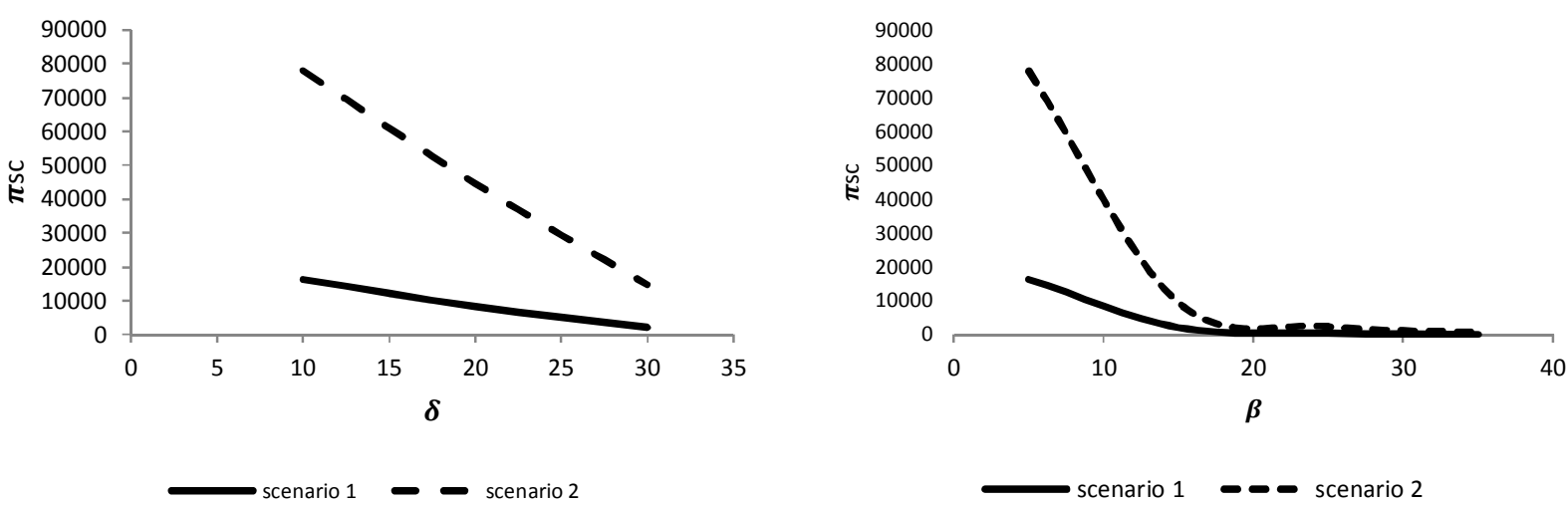

Fig. 4. The expected whole supply chain profit function in terms of $\beta$ and $\delta$

According to fig 3, the expected profit function in terms of $\beta$ and $\delta$ for retailer is descending, which means if $\beta$ and $\delta$ rise, the expected profit function of retailer will decrease. However, the sensitivity of functions to $\delta$ is a bit more than $\beta$. Fig 4 shows the sensitivity of the expected whole supply chain profit function in terms of $\beta$ and $\delta$, and as we can observe, by increasing $\beta$ and $\delta$, the whole supply chain profit function decreases.

\section{Conclusion}

In this paper, we have presented a decentralized two-level retailer-supplier supply chain with price and advertising dependent demand. One form of contracts has been assessed and different scenarios of coordination may be simulated, which may help in quantifying the performance measures and the effectiveness of coordination. The first scenario was "No coordination", and the other scenario was 
"coordination with Revenue sharing contract". The preliminary results have indicated that the contract can increase the profit of supply chain members. The proposed models are solved using Game theory approach, Cooperative and Nash equilibrium. Eventually the numerical results have indicated that contracts can make the profit functions much better and the average expected profit in the second scenario -coordination with Revenue Sharing contract- was more than the other scenario.

Since in this paper, the demand is assumed to be dependent upon the retail price and advertisement, we may relax this assumption in future and analyze supply chains where demand depends on price, quality and some other factors. In this paper, we used the exponential function for demand, so in the future; researchers can use the other functions such as Normal and etc. Researchers can extend these models to three-echelon supply chains. They can consider the supply uncertainty that is a very attractive and unfamiliar assumption in this field.

\section{References}

Barbarosoglu, G. (2000). An integrated supplier-buyer model for improving supply chain coordination. Production Planning \& Control, 11(8), 732-741.

Cachon, G. P. (2003). Supply chain coordination with contracts. Handbooks in Operations Research and Management Science, 11, 227-339.

Cachon, G. P., \& Lariviere, M. A. (2005). Supply chain coordination with revenue-sharing contracts: strengths and limitations. Management Science, 51(1), 30-44.

Chen, J. (2011). The impact of sharing customer returns information in a supply chain with and without a buyback policy. European Journal of Operational Research, 213(3), 478-488.

Chen, J., \& Bell, P. C. (2011). Coordinating a decentralized supply chain with customer returns and price-dependent stochastic demand using a buyback policy. European Journal of Operational Research, 212(2), 293-300.

Chopra, S., \& Meindl, P. (2004). Gerenciamento da cadeia de suprimentos: estratégia, planejamento e operação. Pearson Education do Brasil.

Connors, A. F., Dawson, N. V., Desbiens, N. A., Fulkerson, W. J., Goldman, L., Knaus, W. A., ... \& Sheehan, K. (1995). A controlled trial to improve care for seriously iII hospitalized patients: The study to understand prognoses and preferences for outcomes and risks of treatments (SUPPORT). Jama, 274(20), 1591-1598.

Emmons, H., \& Gilbert, S. M. (1998). Note. The role of returns policies in pricing and inventory decisions for catalogue goods. Management science, 44(2), 276-283.

He, Y., Zhao, L., \& He, J. (2008, January). Supply chain coordination using returns policy with sales rebate and penalty under effort and price dependent demand. In Hawaii International Conference on System Sciences, Proceedings of the 41st Annual (pp. 91-91). IEEE.

Hua, Z., \& Li, S. (2008). Impacts of demand uncertainty on retailer's dominance and manufacturerretailer supply chain cooperation. Omega, 36(5), 697-714.

Hou, J., Zeng, A. Z., \& Zhao, L. (2010). Coordination with a backup supplier through buy-back contract under supply disruption. Transportation Research Part E: Logistics and Transportation Review, 46(6), 881-895.

Kanda, A., \& Deshmukh, S. G. (2009). A framework for evaluation of coordination by contracts: a case of two-level supply chains. Computers \& Industrial Engineering, 56(4), 1177-1191.

Kandel, E. (1996). The right to return. Journal of Law and Economics, 39, 329-356.

Leng, M., \& Parlar, M. (2010). Game-theoretic analyses of decentralized assembly supply chains: Noncooperative equilibria vs. coordination with cost-sharing contracts. European Journal of Operational Research, 204(1), 96-104.

Lovejoy, W. S. (1999). Integrated Operations. Southwestern College Publishing, Cincinnati, OH.

Mahajan, S. (2010). A quantity flexibility contract in a supply chain with price dependent demand. OPSEARCH, 1-16. 
Pasternack, B. A. (2008). Optimal pricing and return policies for perishable commodities. Marketing Science, 27(1), 133-140.

Pellegrini, L. ( 1986). Sale or return agreements versus outright sales. In: Pellegrini, L., Reddy, S.K. (Eds.), Marketing Channel: Relationships and Performance. Lexington Books, Lexington, 59-72.

Petruzzi, N. D. (1999). Pricing and the newsvendor problem: A review with extensions. Operations Research, 47 (2), 183-194.

Sethi, S. P., Yan, H., \& Zhang, H. (2004). Quantity flexibility contracts: Optimal decisions with information updates. Decision Sciences, 35(4), 691-712.

Simchi-Levi, D. (2009). Designing and managing the supply chain concepts strategies and case studies. Tata McGraw-Hill Education.

Tsay, A. A. (1999). The quantity flexibility contract and supplier-customer incentives. Management Science, 45(10), 1339-1358.

Yao, Z., Leung, S. C., \& Lai, K. K. (2008). Analysis of the impact of price-sensitivity factors on the returns policy in coordinating supply chain. European Journal of Operational Research, 187(1), 275-282.

Wang, T., \& Hu, Q. (2010, March). Coordination of supply chain with advertise-setting newsvendor. In Advanced Computer Control (ICACC), 2010 2nd International Conference on (Vol. 1, pp. 391-395). IEEE.

Weng, Z. K. (1995). Channel coordination and quantity discounts. Management Science, 41(9), 15091522.

\section{Appendix}

For two scenarios and cooperative channel, we prove the optimality of the obtained solution in 3 steps:

1. The value of $q$ is obtained by taking the derivative of retailer's expected profit function, and it is optimal when the retailer's expected profit function is concave to $q$.

The value of $q$ is replaced in retailer's expected profit function, so $p$ and $E$ are obtained by taking the derivative of retailer's expected profit function. They are optimal solution when:

2. The retailer's expected profit function is concave respect to $p$.

3. The hessian matrix determinant is negative definite respect to $p$ and $E$.

\section{Scenario 1}

\section{Step 1.}

$$
\frac{d^{2} \pi_{r}}{d q^{2}}<0 \rightarrow \frac{2 p-1}{a-b}<0
$$

So the retailer's expected profit function is concaved to $q$

\section{Step 2}

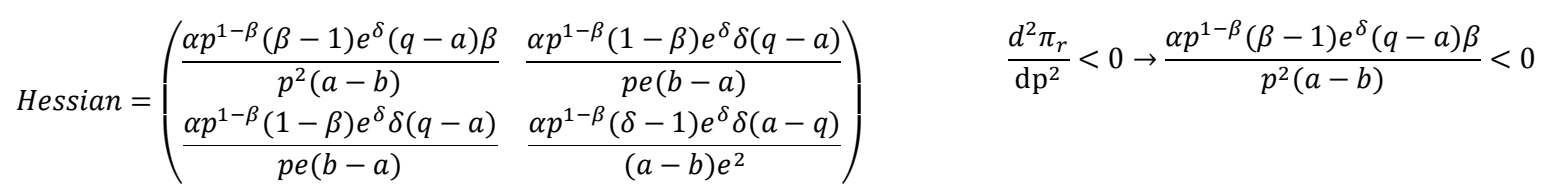


Step 3

$$
\text { if } \beta<\delta \rightarrow \text { determinant }=-\frac{\delta \alpha^{2}\left(p^{1-\beta}\right)^{2}(\beta-1)(\beta-\delta)(a-q)^{2} e^{2 \delta}}{p^{2} e^{2}(a-b)^{2}}>0
$$

Thus the hessian matrix in terms of $p$ and $E$ is negative definite.

\section{Scenario 2}

Step 1.

$$
\frac{d^{2} \pi_{r}}{d q^{2}}<0 \rightarrow \frac{\varphi(2 p-1)}{a-b}<0
$$

So the retailer's expected profit function is concaved to $q$

\section{Step 2.}

$$
\text { Hessian }=\left(\begin{array}{lll}
\frac{\varphi \alpha p^{1-\beta}(\beta-1) e^{\delta}(q-a) \beta}{p^{2}(a-b)} & \frac{\varphi \alpha p^{1-\beta}(1-\beta) e^{\delta} \delta(q-a)}{p e(b-a)} \\
\frac{\varphi \alpha p^{1-\beta}(1-\beta) e^{\delta} \delta(q-a)}{p e(b-a)} & \frac{\varphi \alpha p^{1-\beta}(\delta-1) e^{\delta} \delta(a-q)}{(a-b) e^{2}}
\end{array}\right) \quad \frac{d^{2} \pi_{r}}{\mathrm{dp}^{2}}<0 \rightarrow \frac{\varphi \alpha p^{1-\beta}(\beta-1) e^{\delta}(q-a) \beta}{p^{2}(a-b)}<0
$$

Step 3.

$$
\text { if } \beta<\delta \rightarrow \text { determinant }=-\frac{\delta \varphi^{2} \alpha^{2}\left(p^{1-\beta}\right)^{2}(\beta-1)(\beta-\delta)(a-q)^{2} e^{2 \delta}}{p^{2} e^{2}(a-b)^{2}}>0
$$

Thus the hessian matrix in terms of $p$ and $E$ are negative definite.

\section{Cooperative channel}

Step 1.

$$
\frac{d^{2} \pi_{r}}{d q^{2}}<0 \rightarrow \frac{2 p-1}{a-b}<0
$$

So, the retailer's expected profit function is concave to $q$

Step 2.

Hessian $=\left(\begin{array}{lll}\frac{\alpha p^{1-\beta}(\beta-1) e^{\delta}(q-a) \beta}{p^{2}(a-b)} & \frac{\alpha p^{1-\beta}(1-\beta) e^{\delta} \delta(q-a)}{p e(b-a)} \\ \frac{\alpha p^{1-\beta}(1-\beta) e^{\delta} \delta(q-a)}{p e(b-a)} & \frac{\alpha p^{1-\beta}(\delta-1) e^{\delta} \delta(a-q)}{(a-b) e^{2}}\end{array}\right) \quad \frac{d^{2} \pi_{r}}{\mathrm{dp}^{2}}<0 \rightarrow \frac{\alpha p^{1-\beta}(\beta-1) e^{\delta}(q-a) \beta}{p^{2}(a-b)}<0$

Step 3.

$$
\text { if } \beta<\delta \rightarrow \text { determinant }=-\frac{\delta \alpha^{2}\left(p^{1-\beta}\right)^{2}(\beta-1)(\beta-\delta)(a-q)^{2} e^{2 \delta}}{p^{2} e^{2}(a-b)^{2}}>0
$$

Thus the hessian matrix in terms of $p$ and $E$ is negative definite. 